\title{
Determining safety criteria for reinforced concrete structures of power plants taking the example of a nuclear power plant with RBMK
}

\author{
Valery Nikolayev ${ }^{1}$, Dmitriy Nikolayev ${ }^{1}$ and Anton Yakushev $^{1 *}$ \\ ${ }^{1}$ AO Atomenergoproyekt, 107996, ul. Bakuninskaya, 7 p. 1, Moscow. Russia
}

\begin{abstract}
The paper shows how safety criteria of nuclear power plants with reactor RBMK can be defined based on analytical, numerical and mixed calculation methods using data about strength characteristics of materials with the course of time.
\end{abstract}

\section{Introduction}

Buildings and facilities for use of nuclear power are qualified as super-critical structures according to [1]; this means that they call for extreme safety requirements. Monitoring of the condition of building structures is highly important for assurance of safety. Monitoring includes not merely registration but also analysis of measured physical values. Such analysis compares recorded values with respective permissible high or criterion. Criteria values are thresholds that trigger the near-emergency or emergency status according to [24] and [5]. At this time, two levels of criteria values are assigned: alert and alarm. The alerting level of safety criteria leaves room for the control parameter being incremented by a value that corresponds to a particular load; whereas the alarm level switches the structure to the emergency (near-emergency) state. In other words, the alerting criterion is the emergency criterion diminished by a value expected from specific impact (seismic shock, blast wave, falling aircraft, etc.) [6-8]

For concrete structures, monitoring is carried out to control opening of cracks, rebar stress and, if need be, also structural material temperature and compressive loads inside concrete, focusing on stress in compressed rebar assuming they undergo deformation together [9]. Stress of rebar material and opening fissures are typically measured by means of string devices. Each specific sensor is assigned its own specific safety criterion to take into account the stress of the structure around the sensor, plus the geometry and dimensions of the cross-section and characteristics of concrete and rebar material. If the main crack opens in zones not covered by a sensor, stress can be measured by the extent of the opening crack [2-4]; also, the unloading method can be used for greater accuracy when stress level boarders on the criterial values [10].

\footnotetext{
* Corresponding author: Yakushev_AA@aep.ru
} 
Building structures of power plants and facilities frequently have areas where access to the most stressed aspects of the structure is either limited or impossible. For example, consider rooms with high level of ionizing radiation or a structure with one side exposed to water or soil. In such cases, stress level can be measured indirectly by rebar force gage installed wherever accessible on the rear side.

The resulting monitoring criteria (comparing major factors of technical condition with criterial values) [10] were applied to the "hot" boxes and rooms in a nuclear power plant (NPP) with a RBMK (Power Units One and Two of Smolensk NPP, and Power Units Three and Four of Kursk NPP), where cooling system for concrete became unusable due to lost tightness in water screen pipes.

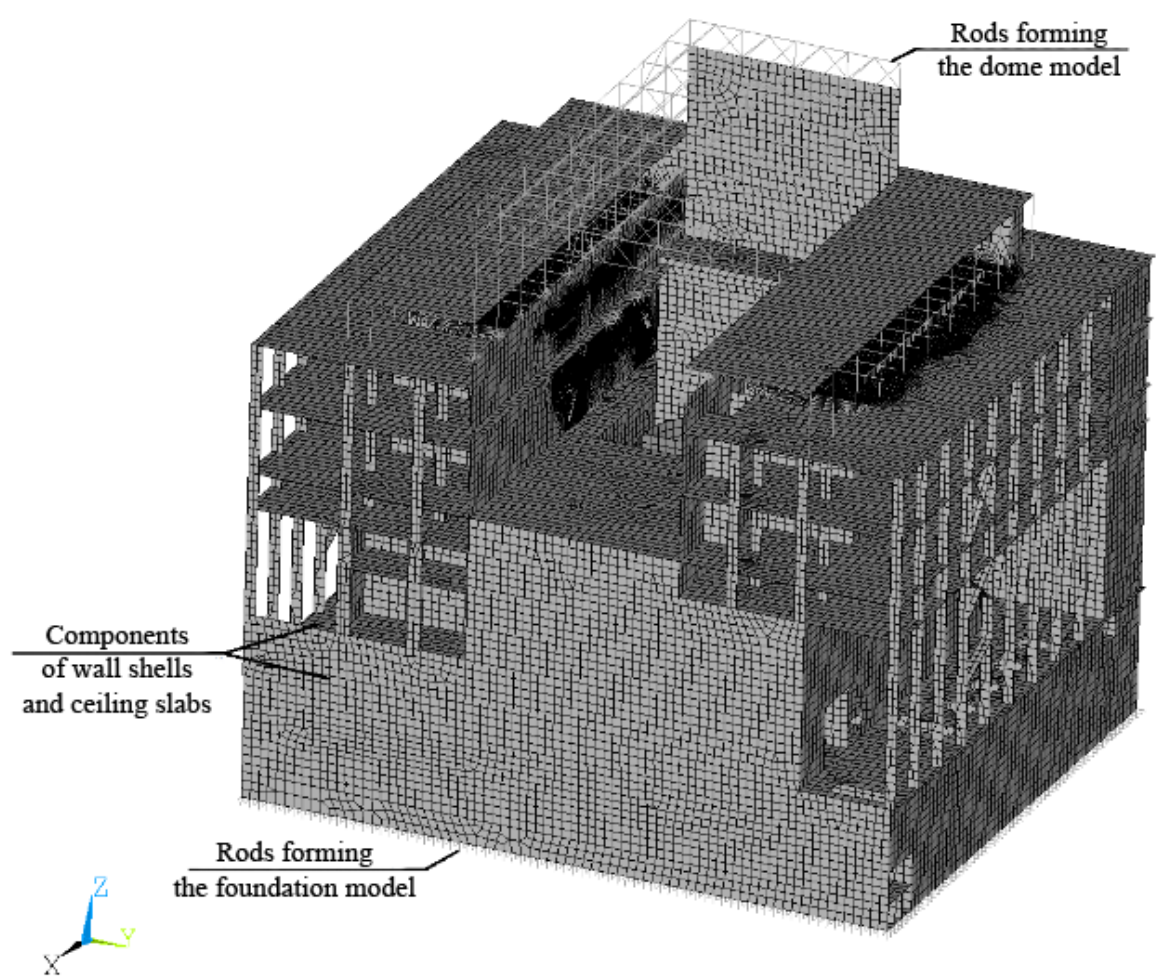

Fig. 1. Standard calculation model of a RBMK unit 


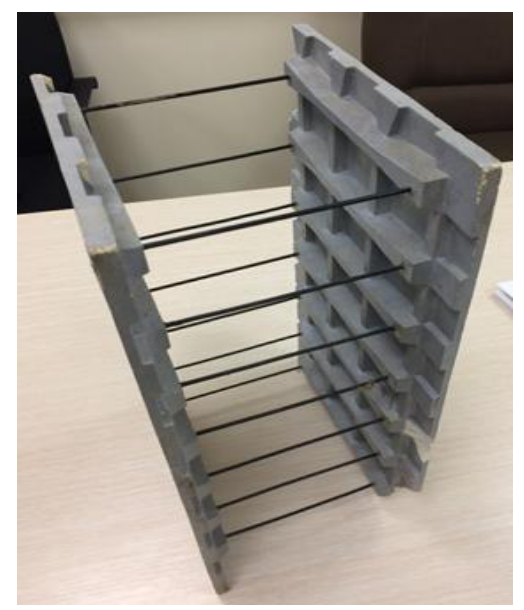

Fig. 2. Rebar panels layout model

Power unit structures undergo considerable stress caused by thermal impacts beyond their designed level. Stress inside the walls and ceilings of the power units is monitored scores of rebar material dynamometers, each installed on the outer side of hot rooms (see Fig. 1). To measure stressed conditions in a power unit, an associated finite element model was developed (see Fig. 2). The power unit's walls were designed to be built as precastmonolithic. As prefabricated components, 3x6 m (two-directional) ribbed reinforcement panels are used, with maximum rib height of $200 \mathrm{~mm}$ (see Fig. 2). Longitudinal working rebar is placed inside the ribs.

$$
\sigma_{s}=E_{s} \cdot \frac{R_{b, m}}{E_{b, \tau, m} \cdot k_{n}}
$$

where $\sigma_{s}-$ stress in reinforcement steel;

$E_{s}$ - modulus of elasticity of reinforcement steel;

$R_{b, m}$ - calculated resistance of filling concrete to axial compression;

$E_{b, \tau, \mathrm{m}}-$ continuous deformation module of filling concrete;

$\mathrm{k}_{\mathrm{n}}$ - irregularity factor for compressive stresses on the structure's faces, caused by onesided heating of surfaces and emergency pressure (2):

$$
k_{n}=\sigma_{t, \text { hot. }}+\sigma_{\text {press }} \sigma_{t, \text { armdyn }}-\sigma_{\text {press }},
$$

where $\sigma_{t \text {,armdyn }}, \sigma_{t \text {,hot. }}$ - normal stress in reinforcement steel from temperature on the side of the rebar dynamometer and on the side of the hot room, respectively;

$\sigma_{\text {seism }}-$ stress in reinforcement steel caused by seismic factor;

$\sigma_{\text {press }}$ - stress in reinforcement steel caused by emergency pressure;

As monolithic layer of concrete shrinks it gets stressed due to hanging on rebar panels (Fig. 3). Tensile stresses are described with this equation (3):

$$
\sigma_{m}=\frac{0.5 \alpha_{y}}{h_{m} \frac{1}{2 h_{p} E_{b, p}}+\frac{1}{E_{b, m}}\left(1+\frac{\varphi_{b, c r, m}}{4}\right)},
$$

where $\sigma_{m}$ - shrinkage stress in the filling concrete;

$\alpha_{y}$ - creep of concrete;

$h_{m}$-filling concrete section height; 
$h_{p}$ - reinforcement panel section height;

$E_{b, p}$ - initial modulus of elasticity of the filling concrete on compression;

$E_{b, m}$ - initial modulus of elasticity of the filling concrete on compression;

$\varphi_{b, c r, m}-$ filling concrete creep ratio

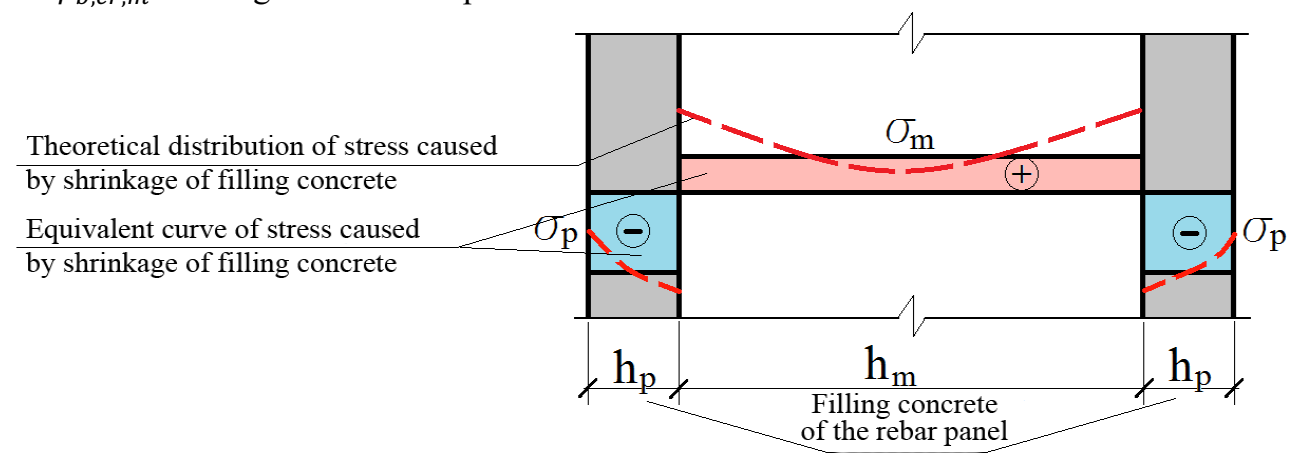

Fig. 3. Illustration of measured stress caused by shrinkage of the filling concrete

Stress in precast concrete caused by shrinkage taking into account the creep of in-situ concrete is described with equation (4):

$$
\sigma_{p}=\sigma_{m} \cdot \frac{h_{m}}{2 \cdot h_{p}}
$$

Stress in reinforcement steel caused by shrinkage taking into account the creep is described with equation (5):

$$
\sigma_{s p}=\sigma_{p} \cdot \frac{E_{s}}{E_{b, p}}
$$

Sum total $\sigma_{\mathrm{s}}$ of stress in reinforcement steel and total shrinkage stress taking into account creep $\sigma_{s p}$ less stress caused by specific loads $\sigma_{\text {seism }}$ and $\sigma_{\text {press }}$ qualify as the alerting safety criterion (6):

$$
\sigma_{s s}=\sigma_{s}+\sigma_{s p}-\sigma_{\text {seism }}-\sigma_{\text {press }}
$$

The monolithic structures, the approach to the definition of the criteria does not change fundamentally: during shrinkage, reinforcement steel rather than precast structure acts as the decelerating element.

If the section has a compressed and extended reinforcement steel, the height of the compressed zone of concrete $(x)$ and stress in the extended reinforcement steel $\left(\sigma_{s}\right)$ should be found from the equilibrium equations (7) and (7a). Torque (M) and longitudinal force (N) should be found in advance through calculation based on the associated model. The strength of concrete $R_{b}$ is assumed based on varying strength of precast and in-situ layers of concrete, in proportion to the area of the compressed zone curve diagram (Fig. 4). The solution is iterative, and we check the height of the compressed zone and respective concrete strength after each iteration step. The resulting stresses $\sigma_{\mathrm{s}}$ less seismic load and emergency pressure load will be in fact the alerting criterion.

$$
\left\{\begin{array}{c}
N=N_{b}+N_{s}^{\prime}-N_{s} \\
M=M_{b}+M_{s}^{\prime}+M_{s}
\end{array}\right.
$$




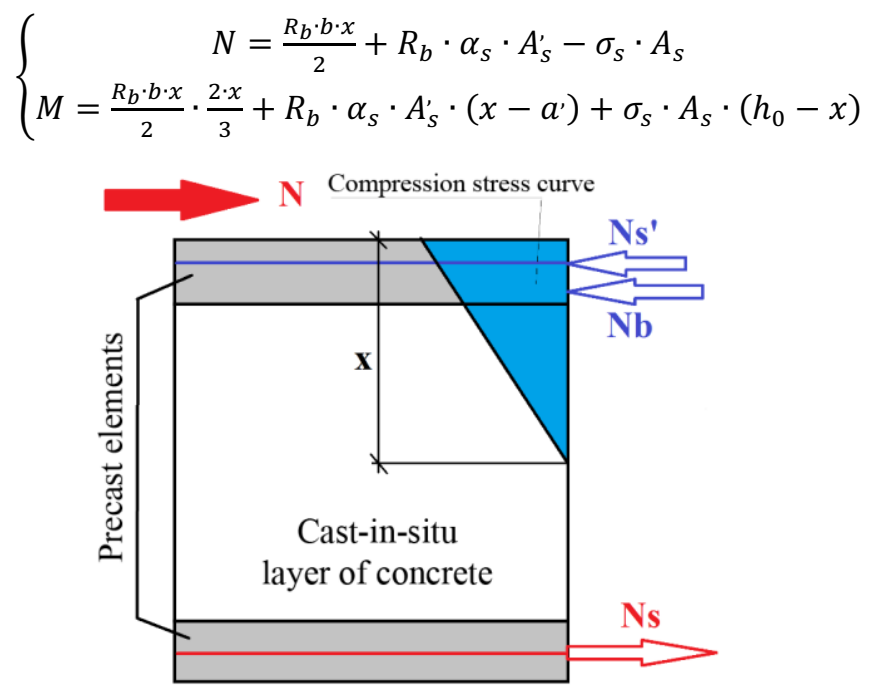

Fig. 4. Illustration of criterion calculation to control expansion stress

If the structure has any cracks or other discontinuities commensurable with the resolution threshold of the numerical method adopted, such flaws should be incorporated in the calculated model [2].

As inputs used to determine the safety criteria, we can use not only the forces existing inside the structures, but also directly stress in core elements that simulate reinforcement steel.

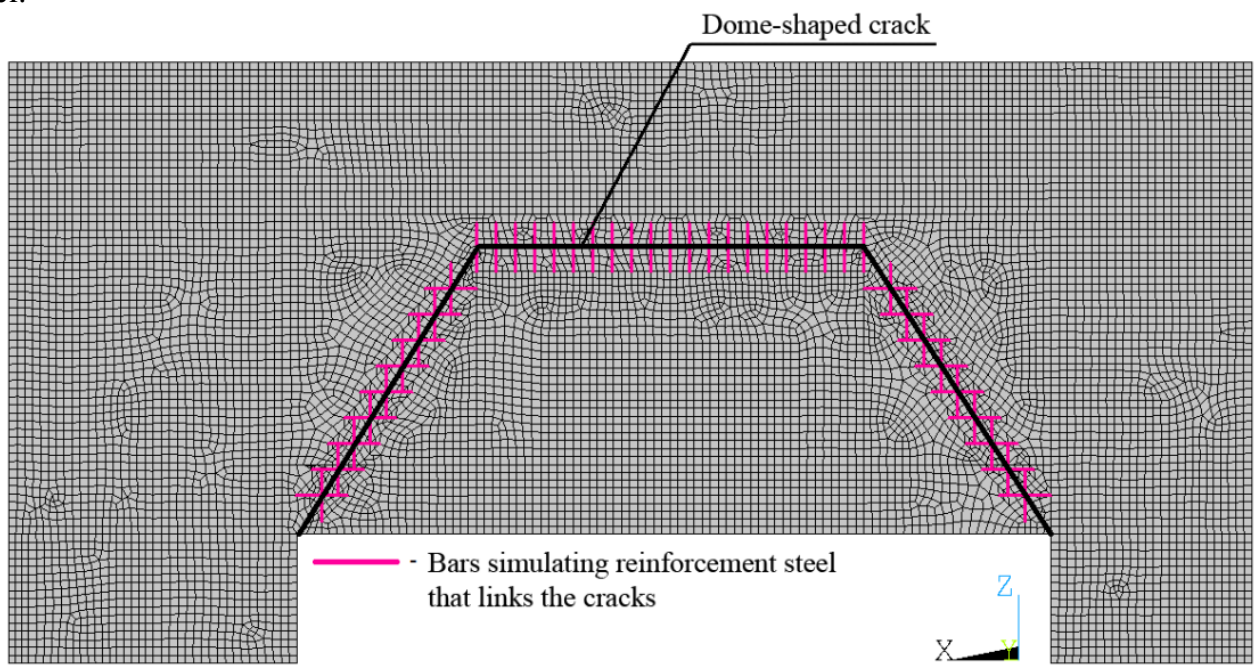

Fig.5. Simulation of cracks in the Central Hall

For example, in the course of operation of the aforesaid NPP units, the walls of the Central Room developed cracks opening in excess of the regulated limits. Existence of a special 24-m long service embrasure predetermined the character of cracks emerging in the walls, as in a wall beam. The areas around supports register oblique cracks created by impacting vertical loads that tend to meet under the LUM console, which results in the formation of the so-called dome-shaped crack, setting out a wall segment connected to the 
rest of the wall virtually by reinforcement steel alone. In the mathematical model of the structure, shell elements have gaps in the cracked areas and are connected with reinforcement bars that simulate reinforcement steel (see Fig. 5).

\section{Conclusion}

We have developed a methodology to address the key safety criterion: stressed condition of reinforcement steel and concrete in a reinforced-concrete structure. Safety criteria for power plants can be defined based on analytical, numerical and mixed calculation methods; they also rely on field data and take into account compromised strength characteristics of materials with the course of time.

\section{References}

1. Town Plan. Code of the Russ. Fed. (2016)

2. GOST 31937-2011 Buildings and Structures. Rules for Examination and Monitoring of Technical Condition. Minregion of Russia (Moscow, 2011)

3. A.V. Korgin, Y.I. Kudishin, V.A. Ermakov, M.V. Emelianov, L.Z. Zeid Kilani, Int. Jour. of App. Eng. Res., 11, 1680-1686 (2016)

4. Valintinovich, K.A., Uriy Ivanovich, K., Leys Zeidovich, Z. Int. Jour. of App. Eng. Res., 10, 43139-43142 (2015)

5. RD 153-34.2-21.342-00 Methods to Determine Safety Criteria of Hydraulic Facilities (Moscow, RAO UES of Russia, 2001)

6. F.F. Bryukhan', A.Y. Vinogradov, A.A. Lavrusevich, At. En., 118, 365-368 (2015)

7. F.F. Bryukhan', A.D. Potapov, At. En., 115, 346-350 (2014)

8. V.V. Potapov, A.M. Loginov, V.A. Il'in, V.G. Kolomiets, A.P. Pustovgar, At. En., 119, 380-383 (2016)

9. B.K. Bylkin, A.N. Kozhevnikov, I.A. Engovatov, At. En., 118, 436-441 (2015)

10. RD EO 1.1.2.99.0007-2011 Standard Manual on Operation of Production Buildings and Facilities for Nuclear Power Plants.

11. RD EO 0462-03 Methodology for Validation of Service Life of Structures in Buildings and Facilities for Nuclear Power Plants. 